\title{
Digital Education in India: Future Perspective and Challenges
}

\author{
Atul Gupta, Ona Ladiwal \\ Department of Management Studies, Swami Keshvanand Institute of Technology, Management \& Gramothan, Jaipur- \\ 302017(INDIA) \\ Email:atul.gupta@skit.ac.in, ona.ladiwal@skit.ac.in \\ Received 6.10.2021, received in revised form 18.10.2021, accepted 18.10.2021 \\ doi: 10.47904/IJSKIT.11.2.2021.87-92
}

\begin{abstract}
In India learning from the electronic medium (e-learning) will shape the way for improved learning strategies in education methodology. Now a day education sector is using various advance tech-tools and platforms for better learning experiences. Through the web entrance rate assessed to get over $55 \%$ before the end of year 2025 in India. Digitalization of education stays one of the highest needs of our present Indian administration as well as society by large. Taking the sign, numerous elearning entryways have showed up and are showing great results as an expanding number of students enlist themselves for online courses - the new ordinary/ normal post the pandemic. In the Beginning 2020, Indian colleges, Institute and schools, which were prior not allowed to offer more than $20 \%$ of a degree through online education, are presently stimulating the limitations on internet figuring out how to extend admittance to advanced education. It also increases the image of Indian education system worldwide. Numerous technological based colleges or organizations have likewise surfaced and are offering learning the executives' assets, including mixed learning, 3D and self sustained units and Artificial Intelligence based experiential and intelligent knowledge, to give an unparalleled encounter. The present study is descriptive based which study the future perspectives of digital education in India. The study also depicts the scope and challenges of the digital education with focus on Indian system and resources in the country. The data collected was focused on secondary based. The paper has importance in the present era of post-covid which mainly affects the education sector and the learning of the students from past two years. So the research got its prominent importance. Not only government but the society, students and parents were facing the problem.
\end{abstract}

Keywords- Education Sector, Pandemic, Digital technology, Infotainment.

\section{INTRODUCTION}

Submit Education is the significant and indispensable part in the overall development of individuals. It also contributing immeasurably in building the nation considering many facets. Throughout some undefined time frame many changes have happened in various areas of economy including the framework of education sector. For the revolutionary global changes in the recent times, education is one of the important sectors. Education sector has seen many changes in its advancement.. From open class room which was conducted under a tree to guru ashram to closed class room lectures. Added to this is the presentation based classes with LCD projector, OHP \& with more aided technologies and equipments. Now a day Whatsapp is the buzzword in education sector. Whatsapp has now become the status of being authentic formal means of communication and sharing meaningful information among the students and the academicians.[1]

In India, from most recent couple of years there has been a significant ascent in digital and shifting classrooms to Live virtual platform at various degrees of learning and knowledge. But due to the pandemic situation of Covid-19 the digitalization in education sector is noteworthy. Whether it is conducting online classes, FDP, Seminars \& Conferences for the students; the use of various virtual platform like google meet, Microsoft teams, Zoom app, Webex and many other has significantly increases. Education through digital platform is fun learning for all cadres and particularly effective for kids knowledge as the inventive sound video include helps the psychological components in a kid's mind. Digital education is offering both teacher and students new prospects to teach, learn and excel. Education institutes are increasingly adopting digital teaching methods in their academic learning process and thereby striving to make the classroom atmosphere more encouraging and participatory. In other words we can say that the digital learning is Info-tainment i.e. combination of both information and entertainment.

\section{DIGITAL EDUCATION IN INDIA}

It is right to say that digital edification is the future of learning. Digital education in India is going to be the new and important visage of upcoming education system. It is astonishing to see, especially after the pandemic Covid-19 situation, that how smart technologies are altering the overall framework of education process in the country. For complete academic year the education and learning of the students irrespective of their class (i.e from preprimary to post graduate) is completely dependent on the e-platform. The entrance of advanced education system into the encompassing region is developing quick. Moderate high velocity web and direct-togadget advancements are enabling understudies to 
examine courses on the web and work on their abilities and information.[2]

The accretion of digital technologies is bringing essential changes in the way education is being conveyed and established. With the digitalization of education the exceed programs for education is improving day by day. It is providing a great platform $\&$ opportunities for both teachers and students to teach and learn thereby ensuring better participation in the overall learning process.

The condition of education in India is miserable, particularly in rustic regions. The education is empowering and redefining. The present education sector is combating with grave difficulties like obsolete showing strategies, lack of educators, deficient understudy instructor proportion, and inadequate instructing assets. The innovation is likewise assisting educators with associating with understudies distantly spread across a few areas all at once. Intuitive advanced media will surely help in tending to the deficiency of educators in the country soon. For the crowded nation like India training isn't just for adapting however it is likewise considered as an establishment for discipline, inventiveness, advancement and a significant way to dispense with the endless loop of obliviousness and destitution from the general public. It will prompt work age and working on the economic wellbeing and expectation for everyday comforts.

As the Government of India has enunciated the New Education Policy 2020, it is seems that education is the forefront of the government and it is the national agenda. The objectives of the parents and the children are growing considerably. Educational transformation for $21^{\text {st }}$-century should be the requirement into the mainstream thinking of the government, with an priority on expansion, excellence, and equity.[3] The government is also taking many initiatives and announced to open various IITs and IIMs, about 900 Universities along with the increased funding and Right to Education Bill. But somehow it is proving only a statement by the government as the intent was not so clear. For example, in 2020-2021 budget the government spent only 3.2 per cent of GDP on education, down from 4.14 per cent in 2014-2015. It means government has reduced education spending by 25 per cent. Though government has announced many programs for Digital India but in the recent budget the no fund was allocated to develop the digital education platform.

\section{Review of Literature}

In the present study many literature was review. Some of them major contribution were as follow:

Jayesh M. Patel (2017). He affirmed that there are many electronic instruments which can be utilized in the study hall for advanced instruction like twitter, Dropbox, and Prezi, Orkur, Instragram. Educators and students are keen on adapting online computer based education but due to the absence of information they are not starting something similar. Further he opined that electronic apparatuses will make the picking up intriguing and understudies will get roused which ordinary study hall can't do. Presently the instructor driven methodologies are making getting the hang of exhausting in any event, for intriguing parts, utilization of advanced innovation makes in any event, exhausting substance fascinating and happy. The idea of kid focused methodology will be satisfied distinctly with the assistance of computerized innovation.[4]

Jinal Jani and Girish Tere (2015). In their findings opined that computerized India program presented by administration of India is significant for the advancement of advanced instruction in the country. Computerized India constrain is an undertaking started by Indian Government for making of advanced engaged society the nation over. Further they stated that iIt will help in assembling the ability of data innovation across administration offices and facilitates in conveying the various government's projects and administrations. Advanced India will help in making position, giving fast web and computerized storage framework, etc. Advanced India has three significant segments in particular computerized frameworks creation, computerized conveying administrations and assets and advanced instruction.[5]

Himakshi Goswami (2016). She stated that the examination featured the various chances and difficulties of computerized India program in India. Computerized India program presented by administration of India will facilitate in changing country interested in a carefully engaged economy. This will assist administration of India to coordinate the Government Departments with individuals of India. Further she elaborated that the fundamental motivation behind this program is to decrease the desk work. It depicts the various chances of the program for individuals of the country. India is having various dialects, culture, and customs, food propensities. The motivation behind advanced India program is to incorporate entire nation carefully however dialects would be the principle challenges in the execution of such program.[6]

Shikha Dua et al., (2015). She examined the various concerns, patterns and difficulties of computerized instruction in India and recommended the engaging ingenious homeroom approach for learning. The upcoming pattern of computerized schooling incorporates digitalized study hall, learning through videos and using playoffs for better learning, etc. she mentioned the various difficulties of computer training in India and the recommended steps to overcome this difficulty. Consistent changes needed in schools and instructor for the improvement of computerized training in India.[7]

\section{RESEARCH METHODOLOGY}

The primary focal point of the present research used Qualitative examination method. It gives a total 
situation of the circumstance fully intent on comprehension of conduct and between relations. The examination is basically founded on the secondary data $\&$ information. The examination for this study was led through writing audit, with no primary work being led. An enormous asset of composed material was utilized, which included books magazine articles, scholastic diaries, and websites.

\section{IMPORTANCE OF DIGITAL EDUCATION}

Our today world is not quite the same as what it was not many years back. Each child/students are experiencing childhood in a totally different world than that of their folks. Presently a day PCs, phones, YouTube, Twitter, Netflix, and Facebook are established in our every day lives. Indeed, even toys with which our children are playing are computerized, and a large number of them are programmable. At the point when we talk about computerized training it is significant in the present advanced world. Few significance of advanced education based on digital technology is referenced beneath:

\subsection{Cost Effective Teaching Method:}

With the presentation of new innovation supported learning apparatuses like MOOCs, tablets, savvy sheets and PCs, and so on has changed the manner in which instruction is being conferred in instructive establishments at both school and school level. The Internet of things is further giving to be quite possibly the most savvy approaches to instruct the understudies. It is additionally considering as an incredible framework to join a top notch learning experience for everybody.

\subsection{Facilitates the Collaborative learning:}

Digital schooling helps in spearheading the idea of collective learning. Through computerized training all the insight minds can join to make a special learning experience that surpasses the public limits. Colleges and universities have dispatched computerized devices to encourage admittance to instruction online to acquire the unrest the social consideration.[8]

\subsection{Developing Motor Skills:}

Motor abilities are utilized ordinarily for the duration of our lives. They assist us with moving and do everything from lifting weighty things to composing on a console. Engine abilities and engine control start creating after birth, and will advance as youngsters develop. Having great engine control additionally assists understudies with investigating the chances around them. It helps in fostering the many related spaces of understudies.

\subsection{Improves Decision Making Skills:}

Digital schooling is one constituent which makes an understudy answerable for how they use innovation to cooperate with their general surroundings. Understudy ran over with the new innovation, reformist information and many acquiring regions. Additionally there are such countless online sites that have rivalries which are information acquiring stages for the two instructors and understudies where they can contend just as adapt mentally. It further develops the dynamic abilities.

\subsection{Improved Academic Performance:}

Technology is not just about playing online games or watching animated videos etc. The benefits of technology and especially when it comes to digital education depend on how students, parents and teachers choose to use it to improve learning. Proper use of the learning process helps to create opportunities for effective and meaningful learning and improved academic performance.

\subsection{Enhance Inventiveness:}

Today's readers can use the Internet to research and find text sources, videos, pod casts and presentations related to anything they would like to learn about. It also helped the teacher and students at the top to explore and learn new dimensions and to do research work. It also develops their creative skills.

\section{AVENUES FOR STRONG E-LEARNING PLATFORM}

Effective and robust e-learning requires a number of approaches that can help build a solid foundation for learning in this current environment. These are:

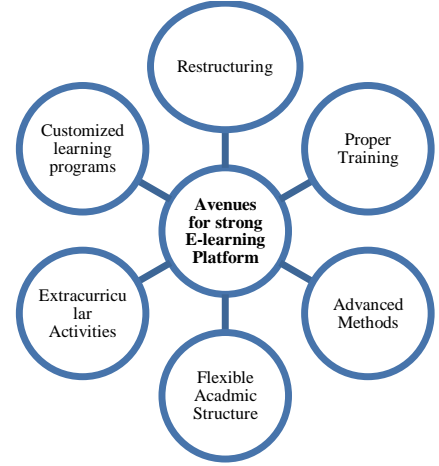

Fig.1 Avenues for Source: Self Generated

\subsection{Restructuring:}

Reliance system dependence is required. From the redesign of the content delivery process to the targeted classrooms focusing on the deep collaboration of the education industry and the adoption of technology is needed. It is difficult to establish a universal pattern in India with the same stroke as it is true of everything when it comes to the world in terms of population, complex structure and determined as India. And like most learning methods, online education helps some students very well, such as those who are selfmotivated and students who are reluctant to speak in a live classroom. Some of the benefits of elearning include things that are not possible in the face-to-face class, such as all students who simultaneously contribute to a document with a collaborative platform. These ever-producing tools are reaping the benefits of e-learning. 


\subsection{Proper Training:}

Pedagogies should evolve as per the requirement of the online classes and proper training should be imparted to the teachers and students so that the new processes of learning can be implemented more effectively. Teaching online demands rational support from the institution to facilitate quality education. The institute must ascertain to have satisfactory institutional resources.[9]

\subsection{Advanced Methods:}

The advanced methods and tools that would help to create a virtual classroom are needed to be further developed. Basic essentials to have a effective online education is required in the best conditions possible. Equipment needs to be renewed and fully operational. The online learning environment allows teachers to go beyond traditional learning methods to incorporate a more inclusive and interactive learning process. Effective learning tools include role-playing and role-playing. Simulation helps students gain skills in a visually safe environment that mimics a real and expensive world.

\subsection{Flexible Structure:}

The educational structure and pattern of the school can be made more flexible through a standard gate or forum for local children to help them compete and grow with their peers outside of their educational institution. Learning about skills or knowledge gained through learning, knowledge or teaching. Online learning is a re-imagining of the educational process that enhances visual classroom software to engage students geographically and geographically to the fullest. This area brings flexibility to the process in terms of planning, content availability, and frameworks, which allows students to find resources there and choose from.

\subsection{Extracurricular Activities:}

As full student development is required then the focus should be on providing essential skills and external activities. This structure is often used for soft skills training focusing on interpersonal interactions. In college settings, an integrated learning approach can be used to teach students to become teachers themselves.

\subsection{Customized learning programs:}

Creating the adaptive and customized learning programs for nurturing the individual requirement and talent is required. The components of $\mathrm{e}$ learning and conventional learning incorporate comparative elements, like inspiration, content boost, freedoms to apply instruction, an evaluation which might involve tests, tests, and exhibitions, and prizes, which are customarily grades that help the accomplishment of a degree or accreditation.[10]

\section{TRENDS OF DIGITAL EDUCATION IN INDIA}

The few trends of digital based education in India are mentioned below:

\subsection{Online Media:}

Online media as a learning tool has improved dramatically. Today, many teachers and students use online media as an integral part of all e-learning information. It is an important stage these days to trade data on important issues. In addition to having the option to share information anytime, anytime, when online media is also a great resource for creating the freedom of planning to integrate social exercise with close work on a financial basis.

\subsection{Intuitive learning Resources:}

With the emergence of smart gadgets such as navigated study halls, portable apps, etc. learning is now not limited to the standard homeroom set. The latest college degree program is reset with these computer resources. Various educators integrate accurate learning modules that utilize the best of new inventions.

\subsection{Integrated learning is enhanced through shared development:}

Organizers, people can connect with others spread around the world to ease tasks and activities. Moreover, the quality of teaching is not limited to one area or another. It is currently not a local obligation that currently follows global transformation. Truth be told, educational foundations acknowledge that providing computerized training is essential to their endurance and development.

\subsection{Monstrous Open Online Courses (MOOCS):}

MOOC classes enable you to study them critically. The spread of online courses through MOOC programs in India is a developing business sector. MOOCs help a ton of young people in the nation rebuild their skills and abilities. Empowering a large number of Indians is not close to rational training so that they can work their jobs through access to a level of skills-based education.[11]

MOOC Learning works with undergraduate and professional students working to study for themselves from anywhere and anytime. Also, the few studies offered under this section provide a lot of evidence that is well known by institutions and organizations as a work ethic. Developing patterns show that India is a huge market for online courses offered in the MOOC category. There is a constantly growing need among students who have tried competent courses and moreover for active leaders to continue to refine their skills for access to opportunities in specific 
regions. For such people, MOOC-based customizations are a great help.

7.5Progression in Visual Learning Aids: AudioVideo based learning is getting pace in India:

Video-based learning is increasingly coming from India: Educational learning recordings are especially popular among school attendees because it joins reading fun. The special mode of instructional learning is very accurate in nature. This type of display system is not limited to audio video but also includes educational programs, webcasts, digital books, etc. Children are very eager to learn new ideas using these computerized methods.

\subsection{Intuitive Software - Game-based learning:}

Game-based learning is the next big thing that will reshape the end of training in India especially the K12 area. It is now creating a climate in which students will no doubt be able to engage with what is especially unsatisfactory teaching. Changing the 12th position, adapting to the game will no doubt disrupt the world of instruction and help build more prepared staff for the future.

\section{CHALLENGES OF DIGITAL EDUCATION}

Inferable from the Covid pandemic, the education sector in India is in emergency right now. Instructive organizations are shut and most presumably, they will stay shut through 2021 because of an expanding number of Covid-19 cases. This could even stretch out to 2022. In the present circumstance online instruction has acted the hero of the reason for schooling. Anyway there are a few difficulties of online schooling and similar should be fixed.

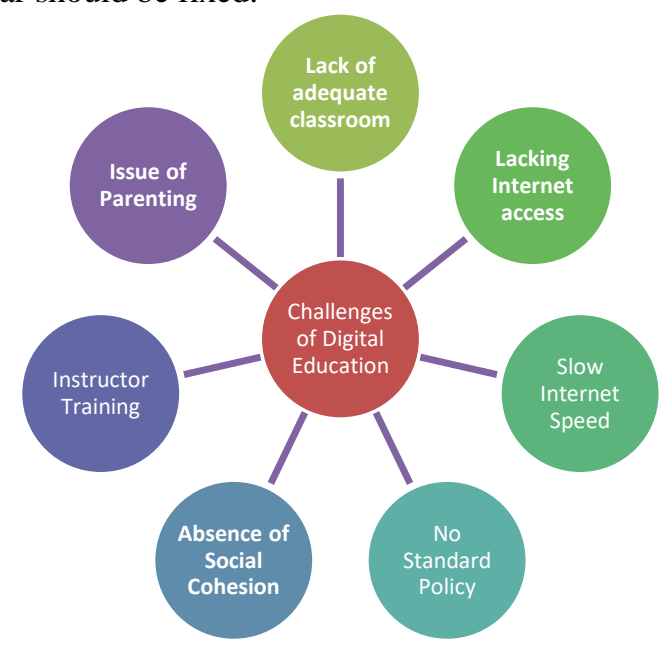

Fig 2. Challenges of Digital Educatin (Source: Self Generated)

\subsection{Lack of adequate Classroom:}

The 2011 Census shows that $71 \%$ of households with at least three people have two-bedroom homes or less (74\% in the country and $64 \%$ in metropolitan districts). In such a case, how can young ones benefit from being taught an uninterrupted sense of belonging?

\subsection{Lack of Internet access:}

According to data from the 2017-18 National Sample Survey, only 42 percent of the metropolitan area and 15 percent of rustic households had access to the web, and only 34 percent of the metropolitan area and 11 people in the province have used the web for the past 30 days. This information explicitly recommends that second / third third of teens be avoided in relation to the online training rate. The worst impact, as always, will be the reduced population, the country and the helpless people.[12]

\subsection{Slow Internet Speed:}

When it comes to learning online, it's about talking to instructors directly about video calls or watching web video addresses, and both require high speed with a consistent web organization. In the absence of sufficient web speed the whole idea will end. We can see the same thing from Jammu and Kashmir's UT where there are regular battles for undergraduates because they can't concentrate without a legitimate web organization.

\subsection{No Standard Policy:}

Digital instruction is not limited to recording lectures or writing on boards of teachers using web tools. It's about the right categories, innovations, devices, ingenuity, duration, content and much more. We do not have a formal program for computer training, foundation, content, communication and multilingualism.

\subsection{Absence of Social Cohesion:}

Educational community organizations alike play a vital role in the integration of friendships and related publications. It is where people, everything is equal, classes, positions, and networks can come together without a forced meeting to bow to other people. This is a basic life lesson that can be improved through online learning.

\subsection{Training of Instructor:}

Instructor care for the mental, emotional and social well-being of children in schools. Training will be coordinated to the full advancement of the human character and to the fortifying of regard for common liberties and key opportunities. Teachers are not prepared enough to submit these lessons through online communication methods.

\subsection{Parental Problems:}

Another challenge is keeping a large number of children out of school when their parents return to work. Adoption and accountability for child safety and learning in the remaining parts of the home is a major problem.

\section{CONCLUSION}

Digital Reading is fun to read for all frames and is a great influence on the learning of young people as the 
visual acuity of thoughtful video helps parts of the brain in a child's brain. The combination of INFOTAINMENT associated with computer literacy makes it more efficient, relevant and addresses our health and environmental aspects in an interesting way.Students see this as a flexible choice that allows them to focus on their time and speed. Educators also think it is helpful to set up their own learning programs with the support of newer students. Teaching turns into a smooth experience with the appropriate lattice of customized piles with a combination of movement, gambling and the effects of mainstream media. Therefore, online teaching and learning strategies deserve our most commendable but in the performance of their official function, which is to improve, support and develop close and independent learning methods. Switching from a teacher's classroom to furthering training will require a lot of effort over time.

\section{REFERENCES}

[1] Srinivasan, M. V., Education in Contemporary India, Pearson, New Delhi, 2019.

[2] https://www.asmaindia.in/blog/future-perspective-of-digitaleducation-in-india/

[3] Best, Jane W., Kahn, James V., and Jha, Arvind K., Research in Education, 10th edition, Pearson, New Delhi, 2017.

[4] Jayesh M. Patel, Web Based Tools Of Technology In Future Teaching Learning Strategies. International Education \& Research Journal [IERJ], 2017. E-ISSN No: 2454-9916 Volume: 3 Issue: 2 Feb 2017.

[5] Jinal Jani and Girish Tere, Digital India: A need of Hours. International Journal of Advanced Research in Computer Science and Software Engineering, 2015, P.8 SSN: 2277 128X

[6] Himakshi Goswam, Opportunities And Challenges Of Digital India Programme. International Education \& Research Journal [IERJ], 2016 E-ISSN No: 2454-9916 Volume: 2 Issue: 11 Nov 2016.

[7] Shikha Dua1, Ms Seema Wadhawan, Ms Sweety Gupta (2016). Issues, Trends \& Challenges Of Digital Education: An Empowering Innovative Classroom Model For Learning. International Journal of Science Technology and Management. Vol. No.5, Issue No. 05. ISSN 2394-1537.

[8] https://indianexpress.com/article/opinion/columns/digitaleducation-online-classes-learning-coronavirus-nationaleducation-policy-6580744/

[9] Aggarwal, J. C. (2008), Development Of Education System In India, Shipra Publications, New Delhi, 2nd edition.

[10] https://www.jagranjosh.com/general-knowledge/impact-ofcoronavirus-on-education-in-india-1587642880-1

[11] https://www.longdom.org/abstract/impact-of-covid-10pandemic-on-education-system-in-india-and-world-wide57328.html

[12] https://www.drishtiias.com/daily-updates/daily-newseditorials/digital-education-in-india. 